\title{
On the Importance of Aging to the Crack Growth Resistance of Human Enamel
}

\author{
Mobin Yahyazadehfar ${ }^{\mathrm{a}, \mathrm{b}}$, Dongsheng Zhang ${ }^{\mathrm{c}}$ and Dwayne Arola ${ }^{\mathrm{a}, \mathrm{d}, `}$ \\ a Department of Material Science and Engineering, University of Washington, Seattle, WA, USA \\ ${ }^{\mathrm{b}}$ Department of Mechanical Engineering, University of Maryland Baltimore County, Baltimore, \\ MD, USA \\ ${ }^{c}$ Department of Mechanics, Shanghai University, Shanghai, 200444, PR China \\ ${ }^{\mathrm{d}}$ Departments of Restorative Dentistry and Oral Health Sciences, School of Dentistry, University \\ of Washington, Seattle, WA, USA
}

Submitted to: Acta Biomaterialia

Support for the following investigation was provided by the National Institutes of Dental and Craniofacial Research (DE016904).

`Corresponding Author

Dwayne D. Arola, Ph.D.

Department of Material Science and Engineering

University of Washington

Roberts Hall 333

Box 352120

Seattle, WA 98195

darola@uw.edu

(206) 685-8158 (v)

(206) 543-3100 (f) 


\title{
On the Importance of Aging to the Crack Growth Resistance of Human Enamel
}

\begin{abstract}
With improvements in oral health and an overall increase in quality of life, the percentage of fully or largely dentate seniors is increasing. Understanding the effects of aging on the mechanical properties of teeth is essential to the maintenance of lifelong oral health. In this investigation the effects of aging on the fracture toughness of human enamel were evaluated from incremental crack growth experiments performed on tissue of donor teeth representing "young" (17 $\leq$ age $\leq 25)$ and "old" (age $\geq 55)$ age groups. Results showed that the old enamel exhibited significantly lower resistance to fracture than that of the young tissue in two orthogonal directions of crack growth. For crack growth transverse to the enamel rods, the fracture toughness of the old enamel $\left(0.37 \pm 0.15 \mathrm{MPa} \bullet \mathrm{m}^{0.5}\right)$ was nearly $70 \%$ lower than that of tissue from the young teeth $\left(1.23 \pm 0.20 \mathrm{MPa} \bullet \mathrm{m}^{0.5}\right)$. Based on results from a mechanistic analysis of crack growth, the reduction in fracture resistance is attributed to a decreased in the degree of extrinsic toughening. The practice of restorative dentistry should account for these changes in tooth tissues in the treatment of senior patients.
\end{abstract}

Keywords - aging; crack growth; fracture; enamel; tooth; toughness 


\section{INTRODUCTION}

Due to many improvements in oral health care, the population of partially- and fullydentate seniors is increasing [1,2]. There are new challenges associated with this growing group of patients. One concern is that tooth fractures occur more frequently in senior patients than in young adults [e.g. 3,4]. Indeed, biological aging is inevitable and it causes detrimental changes to nearly all tissues of the body, including those of teeth [5]. Hence, a better understanding of aging in dental tissues is of critical importance to the field of dentistry.

The importance of aging to the mechanical behavior of hard tissues is not a new topic. In bone, there is a significant reduction in the fracture resistance with increasing age [e.g. 6-9]. Dentin, the major hard tissue of the tooth, also undergoes a reduction in the fatigue strength and fracture resistance with patient age [5,10-14]. The degradation occurring to these hard tissues has been attributed to changes over various length scales, and involves both the mineral content and the organic matrix. Bone and dentin are collagenous tissues and consist of nearly equal parts of mineral and organic components by volume. In contrast, tooth enamel is the most highly mineralized hard tissue of the body and does not contain a collagenous matrix. Therefore, the changes in mechanical behavior of this tissue with age could be quite different from that of bone and dentin.

Enamel consists of approximately $96 \%$ carbonated hydroxyapatite, 3\% water and $1 \%$ protein content by weight. The individual crystallites are combined with a spatially varying amount of organic substance and coalesce into columnar rods, also known as the enamel prisms [15]. The crystal orientation within the rods varies spatially as well. Within the head region the crystals are aligned with the longitudinal axis, whereas those in the tail (or inter-rod) region are oriented obliquely [16]. The interface between adjacent rods is separated by a narrow zone 
sometimes referred to as the rod sheath, and consists of crystallites with less well-defined orientation and a slightly higher degree of organic content. Overall, the proteins serve as the cohesive material between adjacent crystallites and, to a greater extent, at the rod interfaces [17]. There is a change in the distribution of rods across the thickness of enamel. Close to the occlusal surface the rods are aligned and parallel to one another, whereas in the middle and inner layers of enamel they follow a complex undulating path known as decucssation. In evaluations using optical microscopy rod decussation leads to the appearance of alternating bands of reflected light, which are known as "Hunter Schreger bands" [18]. Enamel rod decussation bestows toughness to this tissue and prevents chipping and tooth fractures [19-21].

Due to compositional variations that result from prolonged exposure to the oral environment, human enamel undergoes a reduction in permeability and discoloration with aging [17]. In addition, visual observations of enamel often show that the density of cracks and craze lines increases substantially with aging. Indeed, the hardness and elastic modulus of enamel increase with age [22,23] and they cause an increase in indentation brittleness [24]. While important, previous studies concerning the importance of aging to the mechanical behavior of enamel have been limited to the use of indentation approaches. This study utilizes a combination of experiments and numerical analysis to quantify the contributions of biological aging to the crack growth resistance of human enamel for the first time.

\section{MATERIALS AND METHODS}

Caries free human third molars were obtained from participating clinics in the state of Maryland according to an approved protocol (Y04DA23151) issued by the Institutional Review Board of the University of Maryland Baltimore County. All of the teeth were obtained from donors between 17 and 83 years of age and stored after extraction in Hanks Balanced Salt 
Solution (HBSS) with record of age and gender. Each tooth was inspected at receipt, and any with signs of visible damage or decay were discarded. According to the distribution of donor ages, the collected teeth were divided into "young" $(17 \leq$ age $\leq 25)$ and "old" (age $\geq 55)$ age groups.

Within one month of extraction the teeth were sectioned using a slicer/grinder (Chevalier, Smart H818II) with diamond abrasive slicing wheels and water-based coolant to obtain $2 \times 2 \times 2$ $\mathrm{mm}^{3}$ cubes of cuspal enamel (Fig. 1a). The sectioned enamel cubes were molded within a commercial dental resin composite (Vit-l-escence, Ultra dent Products, Inc., South Jordan, UT, USA) according to Figure $1 \mathrm{~b}$. Detailed descriptions of this process have been described elsewhere $[19,25]$. Additional features were introduced in the molded blocks to develop the basic Compact Tension (CT) specimen geometry, including a back channel (1 $\mathrm{mm}$ deep) and two holes for Mode I loading. Lastly, the notches in each of the inset enamel cubes were sharpened using a razor blade and diamond paste to facilitate the process of crack initiation.

The fracture resistance of enamel was evaluated for crack growth in two orthogonal directions, including parallel to the axis of the rods (longitudinal) and perpendicular to the rods (transverse) as illustrated in Figure 1a. Both directions involve crack growth in-plane with the rods as evident in Figure 1c. In those CT specimens prepared with transverse orientation, sectioning was performed to achieve crack growth in the outer enamel (closest to the occlusal surface), which experiences the largest degree of chemical variations [23,26]. A total of 10 old specimens were evaluated including the longitudinal $(n=5)$ and transverse $(n=5)$ directions. Similarly, for the young group 10 specimens were evaluated in the longitudinal $(n=5)$ and transverse $(n=5)$ directions. Additional sacrificial specimens were prepared for documenting the participating toughening mechanisms. 
The specimens were subjected to a short period of cyclic loading using a commercial universal testing frame (BOSE, Model ELF 3100, Eden Prairie, MN, USA) to initiate a crack from the prepared notch. Thereafter, incremental monotonic loading was conducted to achieve stable crack growth using a dedicated universal testing system complemented with a microscopic imaging system (Optem zoom 70x1 391940, QIOPTIQ, Luxembourg). The initial loading sequence was conducted in displacement control with $1 \mathrm{~N}$ increments followed by a small degree of unloading $(\approx 0.2 \mathrm{~N})$ until the onset of crack extension. Thereafter, the loading was conducted using $0.5 \mathrm{~N}$ intervals to advance the crack incrementally until the point of crack instability. The extent of crack growth achieved in each increment of loading varied with specimen, but decreased in length with increasing crack length. In general, the crack advanced on the order of 100 to $200 \mu \mathrm{m}$ in length each increment of loading. There was a 2 min dwell between each of the loading increments to allow the crack advancement to reach completion. The crack stability was identified from stabilization in the magnitude of opening mode load. Hydration of the samples was maintained during loading using a saturated cotton swab that cradled the specimen and retained moisture applied with an eyedropper of HBSS. Digital images were acquired during each stage of loading and unloading to identify the displacement field and crack lengths using Digital Image Correlation (DIC). A detailed description of the microscopic DIC process and its application to these experiments is given elsewhere [27]. In short, the Crack Opening Displacement (COD) distributions were obtained and used to precisely identify the crack tip from the location of zero opening-mode displacement. In addition, the COD profiles were used within a hybrid approach to determine the contribution of extrinsic and intrinsic toughening mechanisms. 
Using the crack length measurements and corresponding opening mode load from the incremental loading experiments, the stress intensity $\left(\mathrm{K}_{\mathrm{I}}\right)$ distribution was calculated according to [28]

$$
\mathrm{K}_{\mathrm{I}}=\left(\frac{\mathrm{P}}{\mathrm{B}^{*} \sqrt{\mathrm{W}}}\right)\left[\frac{\mathrm{E}_{1}\left(1-v_{2}^{2}\right)}{\mathrm{E}_{2}\left(1-v_{1}^{2}\right)}\right] \sqrt{\frac{\mathrm{B}^{*}+1}{\mathrm{~B}+1}}\left(0.41-1.57 \alpha+2.85 \alpha^{2}\right) \quad\left[\mathrm{MPa} \cdot \mathrm{m}^{0.5}\right]
$$

where $\mathrm{P}$ is the opening load (Newtons) and the quantities $\alpha, \mathrm{B}, \mathrm{B}^{*}$ and $\mathrm{W}$ are measures of the specimen geometry (in $\mathrm{mm}$ ) as illustrated in Figure 1b. The stress intensity distribution is a function of the elastic modulus and Poisson's ratio of the inset $\left(\mathrm{E}_{1}, \mathrm{v}_{1}\right)$ and molding materials $\left(\mathrm{E}_{2}, \mathrm{v}_{2}\right)$ as defined in Equation 1. For both crack growth directions, the elastic modulus and Poisson's ratio of enamel were considered as $30 \mathrm{GPa}$, and 0.29 , respectively, in accordance with the macro-scale mechanical properties [29,30]. These two quantities for the resin composite molding material were $6 \mathrm{GPa}$, and 0.33 according to Yahyazadehfar et al. [28]. Equation 1 is a function of the crack length and specimen according to $\alpha=\mathrm{a} / \mathrm{W}$ and the term $\lambda$, which is given by

$$
\lambda=0.04+0.91 \alpha
$$

For the specimens used in evaluating crack growth in the transverse direction, the width spanned the distance from the DEJ to the occlusal surface of the donor teeth. As such, the fracture surface consisted of a combination of decussated and non-decussated enamel. Decussation of the enamel rods is critical to the fracture resistance of enamel [21,25,31]. Thus, the specimens in this group were evaluated post-failure to quantify the degree of decussation (D) from the ratio of decussated fracture area to total fracture area after Yahyazadehfar et al. [21]. The estimates of D for each transverse specimen provided an objective measure of rod characteristics that were used to differentiate those most representative of outer enamel. The specimens with an average D 
$\leq 40 \%$ were accepted as outer enamel. Measures of the fracture resistance obtained for enamel from the two age groups were compared using one-way ANOVA and Tukey post hoc test using a critical value (alpha) of 0.05 .

\section{Finite Element Analysis}

To quantify the contribution of extrinsic and intrinsic mechanisms to the fracture resistance, a hybrid approach was adopted in which results from the experiments were used as the solution for a finite element model of the fracture process. A detailed description of the hybrid method applied to evaluations on the resistance to fracture of enamel has been presented [32]. Briefly, a 2D half model of the enamel inset CT specimen was developed using commercial software (ABAQUS Standard, Version 6.9, Dassault Systems). The half-model was constructed according to the dimensions of specimens in the experiments, and consisted of approximately 3500 8-node quadrilateral plane strain elements (CPE8R). The constitutive behavior of enamel was defined using a one dimensional Ramberg-Osgood model which accounts for both elastic and inelastic behavior and is defined as [33]

$$
\mathrm{E} \varepsilon=\sigma+\alpha\left(\frac{|\sigma|}{\sigma_{\mathrm{o}}}\right)^{\mathrm{n}-1} \cdot \sigma
$$

where $\sigma$ and $\varepsilon$ are the stress and strain, respectively, $\sigma_{\mathrm{o}}$ is the yield stress, E is Young's modulus, $\alpha$ is the yield offset and $\mathrm{n}$ is the hardening exponent for the plastic (nonlinear) term (where $\mathrm{n}>1$ ). The elastic modulus of enamel was defined as $30 \mathrm{GPa}[29,30]$ with yield strength $\left(\sigma_{\mathrm{o}}\right)$ of 30 MPa [34]. The two parameters of $\alpha$ and $n$ in the Ramberg-Osgood model were estimated by curve fitting to be 0.86 and 20.14 , respectively.

The extrinsic toughening of enamel was simulated with a series of non-linear spring elements distributed with a constant distance of $25 \mu \mathrm{m}$ from one another. The constitutive 
behavior of the springs was modeled according to Figure $2 \mathrm{~d}$, which accounted for damage initiation, damage evolution and failure. The length of the cohesive zone was defined according to experimental observations of the bridging zone, which ranged from $400 \mu \mathrm{m}$ to $1000 \mu \mathrm{m}$, and varied according to the crack direction and length. The parameters associated with the non-linear spring response were adjusted following an iterative process until reaching an agreement between the experimental and numerical COD profiles within 5\% difference. Lastly, the remaining spring loads were documented and the corresponding bridging stresses were calculated by dividing the spring load by the effective area of the springs. After achieving agreement between the experimental and numerical COD profiles, the J-integral for each specimen was estimated numerically using a defined set of 15 contours surrounding the crack tip [35]. Moreover, the energy absorbed by the bridging ligaments and plastic deformation around the crack tip was obtained separately. The total J-integral was calculated according to

$$
\mathrm{J}_{\text {total }}=\mathrm{J}_{\text {tip }}+\mathrm{J}_{\mathrm{pl}}+\int_{0}^{\delta_{1}} \sigma \cdot \mathrm{d} \delta
$$

where $\mathrm{J}_{\text {tip }}$ corresponds to the $\mathrm{J}$-integral due to elastic deformation (i.e. LEFM), $\mathrm{J}_{\mathrm{pl}}$ accounts for the energy spent by plastic deformation around the crack tip (intrinsic toughening), and the integral quantifies the energy exhausted by the work of the posterior ligaments that are represented in the model by the spring elements (extrinsic toughening). The relative contribution of the intrinsic and extrinsic mechanisms to the fracture resistance was estimated from the ratios of the individual components of energy (i.e. of deformation and the individual toughening mechanisms) to the total energy to fracture $\left(\mathrm{J}_{\text {total }}\right)$. Differences in the degree of toughening were evaluated for the two crack growth directions and with regards to the aging process. The apparent toughness was then estimated from the J-integral values according to [35] 


$$
\mathrm{K}_{\mathrm{I}}=[\mathrm{J} \cdot \mathrm{E}]^{\frac{1}{2}}
$$

where $\mathrm{J}$ is either $\mathrm{J}_{\text {tip }}$ or $\mathrm{J}_{\text {total }}$ for estimation of the linear elastic $\left(\mathrm{K}_{\mathrm{c}}\right)$ or effective $\left(\mathrm{K}_{\text {eff }}\right)$ fracture

toughness, respectively, and $\mathrm{E}^{*}=\mathrm{E} /\left(1-v^{2}\right)$ according to the plane strain condition. It is important to note that $\mathrm{K}_{\text {eff }}$ accounts for contributions of the elastic and inelastic deformation, as well as extrinsic toughening.

\section{RESULTS}

Typical load vs load-line displacement curves for quasi-static crack growth within representative specimens of young and old enamel are shown in Figure 3; both of these responses were obtained for longitudinal crack growth. In general, the responses exhibited two distinctive regions of behavior. Region I consists of pre-loading and the elastic respense and an increase in the elastic energy prior to advancement of the crack. At the onset of crack extension there was a distinct drop in the magnitude of opening load. Region II behavior represents the response that follows this event, and is comprised of incremental crack growth until the point of instability. Within the young specimens the initiation of crack growth occurred at loads between 4 and 6 Newtons. In the old enamel crack initiation began at much lower loads, ranging between 2 and 4 Newtons. The length of incremental advancement was dependent on the crack location, its orientation and the donor age group. Overall, the average length of crack extension was approximately $200 \mu \mathrm{m}$. There was a decrease in length from the outer to the inner enamel and the average lengths were much larger in the old enamel. Furthermore, cracks in the old enamel exhibited less stability (i.e. much less Region II behavior) before resulting in catastrophic 
fracture. In fact, the specimens with transverse rod orientation did not exhibit a Region II response as the crack became unstable at the beginning of extension.

A crack growth resistance curve (i.e. R-curve) for the longitudinal direction of crack growth in old enamel is shown in Figure 4a. The R-curves were quantified in terms of three characteristic parameters including the initiation toughness $\left(\mathrm{K}_{\mathrm{o}}\right)$, growth toughness $\left(\mathrm{K}_{\mathrm{g}}\right)$, and apparent fracture toughness $\left(\mathrm{K}_{\mathrm{c}}\right)$. As highlighted in this figure, the $\mathrm{K}_{\mathrm{o}}$ was the stress intensity at which the pre-crack begins to propagate and $\mathrm{K}_{\mathrm{c}}$ was quantified from the maximum recorded stress intensity $\left(\mathrm{K}_{\mathrm{I}}\right)$ before unstable fracture. In addition, the growth toughness $\mathrm{K}_{\mathrm{g}}$ represents the slope of the stress intensity distribution per unit crack extension and was quantified from the last three data points near the point of instability. The R-curves for all the old samples are compared with results for the young enamel in Figure 4b. In the longitudinal direction of crack extension, both age groups exhibited an increase in the resistance to fracture with crack growth. However, the old enamel achieved lower stress intensity before reaching instability. The R-curves obtained for the young specimens exhibited an increase in resistance after roughly $0.5 \mathrm{~mm}$ of crack extension, whereas that did not begin until after almost $1 \mathrm{~mm}$ of crack extension in the old enamel.

Differences in results between the two age groups were more substantial for the transverse direction (Fig. 4c). While the young enamel exhibited rising R-curve behavior, the old specimens underwent unstable crack growth nearly immediately after initiation of the crack, and at relatively modest values of stress intensity $0.20 \leq \mathrm{K}_{\mathrm{I}} \leq 0.45 \mathrm{MPa} \bullet \mathrm{m}^{0.5}$. The average initiation, growth and maximum toughness obtained from the resistance curves of the enamel specimens are listed in Table 1. 
A detailed comparison of the average R-curve parameters for crack growth in the young and old enamel specimens is presented in Figure 5. Results for the initiation toughness are shown in Figure 5a. The average initiation toughness of the old enamel for transverse crack growth $\left(\mathrm{K}_{\mathrm{o}}=\right.$ $\left.0.37 \pm 0.15 \mathrm{MPa} \bullet \mathrm{m}^{0.5}\right)$ was the lowest overall, and significantly lower $(\mathrm{p} \leq 0.05)$ than that for old enamel in the longitudinal direction $\left(\mathrm{K}_{\mathrm{o}}=0.54 \pm 0.11 \mathrm{MPa} \cdot \mathrm{m}^{0.5}\right)$, as well as for both growth directions in the young enamel. Regarding the longitudinal direction of crack growth, there was no significant difference $(\mathrm{p}>0.05)$ in the measures of initiation toughness between the young $\left(\mathrm{K}_{\mathrm{o}}=0.67 \pm 0.12 \mathrm{MPa} \bullet \mathrm{m}^{0.5}\right)$ and old $\left(\mathrm{K}_{\mathrm{o}}=0.78 \pm 0.04 \mathrm{MPa} \bullet \mathrm{m}^{0.5}\right)$ specimens. Regarding the growth toughness (Fig. 5b), the responses for longitudinal crack extension in the old enamel $\left(\mathrm{K}_{\mathrm{g}}=\right.$ $0.64 \pm 0.44 \mathrm{MPa} \bullet \mathrm{m}^{0.5} / \mathrm{mm}$ ) are nearly $75 \%$ lower than those for young enamel. In comparing the maximum resistance to fracture for the two age groups (Fig. 5c), the old enamel exhibited a significantly $(\mathrm{p} \leq 0.05)$ lower toughness than the young enamel in both directions of crack extension. The largest difference between the two age groups was evident in the transverse direction, where the fracture toughness of the old enamel $\left(0.37 \pm 0.15 \mathrm{MPa} \cdot \mathrm{m}^{0.5}\right)$ was nearly $70 \%$ lower than that of tissue from the young teeth $\left(1.23 \pm 0.20 \mathrm{MPa} \bullet \mathrm{m}^{0.5}\right)$.

The contributions of extrinsic and intrinsic toughening mechanisms to the fracture resistance of enamel were estimated quantitatively using the hybrid method. These evaluations were limited to "long cracks" corresponding to stable crack growth in which both the intrinsic and extrinsic components were assumed fully developed. Experimental results for the Crack Opening Displacement (COD) distribution for young enamel are shown in Figure 6a along with predictions from the finite element models. The COD distributions from the models are presented without the introduction of extrinsic mechanisms of toughening (i.e. "traction free"), and with assignment of a cohesive zone (i.e. "cohesive"). Note that the posterior traction forces 
of the bridging elements are necessary to achieve agreement with the experimental COD distribution. A similar comparison of the COD distributions for old enamel is presented in Figure $6 b$.

Estimates of the energy release rate (i.e. J-integral) obtained from the numerical model for the young and old enamel specimens are listed in Table 2. For both age groups the extrinsic toughening mechanisms have the largest contribution to the rise in fracture resistance with crack growth, and contributed approximately $30 \%$ of the total fracture energy. Indeed, the fracture energy corresponding to extrinsic toughening was approximately five times greater than that attributed to inelastic deformation. Comparing the estimated fracture energies for the two age groups, the energy corresponding to extrinsic toughening in the old enamel was approximately $25 \%$ lower than in the young enamel. Furthermore, the energy corresponding to inelastic deformation in the old enamel was approximately $40 \%$ lower than that in young enamel.

\section{DISCUSSION}

Following the investigation reported by Hassan et al. [36], the fracture behavior of human tooth enamel has been studied for a period of more than three decades. Nevertheless, the importance of aging to the mechanical behavior of enamel has received limited attention. The present investigation is the first to explore the contribution of biological aging to the fracture resistance of this tissue using a conventional fracture mechanics approach. Results demonstrated that the crack growth resistance of enamel from the "old" donor teeth was significantly lower than that for young enamel, and in both directions of crack growth evaluated. A number of unique findings were obtained that warrant discussion. 
Regardless of age, the incremental crack growth resistance measurements showed that the enamel exhibited rising R-curve behavior for the longitudinal direction of crack extension (Fig. 4b). Yet, there were some distinct differences in the R-curves for the two age groups. The crack growth responses for the young enamel specimens exhibited a substantially larger growth toughness $\left(\mathrm{K}_{\mathrm{g}}=2.66 \mathrm{MPa} \cdot \mathrm{m}^{0.5} / \mathrm{mm}\right)$ than that obtained for the old specimens $\left(\mathrm{K}_{\mathrm{g}}=0.64\right.$ $\mathrm{MPa} \cdot \mathrm{m}^{0.5} / \mathrm{mm}$ ), which inevitably contributed to the lower fracture toughness achieved overall. Furthermore, toughening in the young enamel specimens began near the onset of crack extension and continued until the crack reached instability. For the old enamel, the onset of crack growth toughening did not begin until the cracks proceeded well within the fully decussated region.

Observations of the crack path for the longitudinal direction showed that similar extrinsic toughening mechanisms were active in the young and old enamel (Fig. 7a), and largely consisted of crack bridging and crack deflection. However, the bridging ligaments in the old specimens developed less frequently, and consisted of a lower number of enamel rod bundles. Those qualities decreased the potency of extrinsic toughening in the old enamel, which was corroborated by a reduction in the crack closure stresses in the old enamel (Fig. 6c). The maximum closure stress was reduced by over $30 \%$ (from 17 to $11 \mathrm{MPa}$ ) over the age span of the two groups, which further conveys that the role of crack bridging is reduced in the old enamel.

The most substantial difference in the fracture resistance of enamel with age was observed for crack growth in the transverse direction, which is equivalent to cracks that are extending about the periphery of the tooth in the outer enamel. For this orientation, the old enamel exhibited approximately $30 \%$ lower initiation toughness and negligible growth toughening $\left(\mathrm{K}_{\mathrm{g}} \approx 0\right)$. Observations of the cracks in the transverse direction showed that they primarily extended along the plane of maximum opening mode stress intensity (Mode I) and that 
there was no clear evidence of extrinsic toughening (Fig. 8a). The path of extension was largely confined to the interface of adjacent rods as evident in Fig. 8b. That behavior is consistent with the observations reported in previous studies for crack extension transverse to the enamel rods as a result of indentations [23] or occurring by incremental crack growth [32].

The importance of aging to the fracture behavior of enamel has been assessed previously using the indentation approach [23,24]. According to results of those studies, there is a $10-20 \%$ reduction in the fracture resistance with age, and the degradation is limited to the outer enamel. It is important to note that the indentation fracture approach evaluates the resistance to the development and extension of a crack under contact. It does not necessarily represent the resistance to crack growth. Consequently, there are concerns regarding its use for estimating fracture toughness [37], especially when applied to biomaterials and hard tissues [38]. A quantitative comparison of the material's toughness estimated by the indentation and conventional methods is difficult [39]. Due to the mechanics involved, the apparent toughness estimated by indentations is potentially most akin to the measure of initiation toughness $\left(\mathrm{K}_{\mathrm{o}}\right)$ obtained using the incremental crack growth responses. Although there was a significant reduction in $\mathrm{K}_{\mathrm{o}}$ with age for the transverse direction (Fig. 4(a)), the most substantial degradation was noted in the crack growth toughening ( $\mathrm{K}_{\mathrm{g}}$ in Fig. $4 \mathrm{~b}$ ). Results from the conventional approach also showed that both $\mathrm{K}_{\mathrm{o}}$ and $\mathrm{K}_{\mathrm{g}}$ are direction dependent. Those qualities were not identified in prior studies performed using the indentation method. Nevertheless, they could be considered most relevant to the potential for tooth fracture arising from incipient cracks on the occlusal surface of teeth $[40,41]$. Based on the degree of reduction in $\mathrm{K}_{\mathrm{g}}$, the degradation in fracture resistance of enamel with age should be considered of substantial importance to tooth survival. 
Despite having a larger degree of decussation $(D=0.34 \pm 0.04)$ than that of the young specimens $(D=0.23 \pm 0.07)$, the fracture resistance curves obtained for the old enamel did not exhibit crack growth toughening in the transverse direction. Hence, in addition to the reduction in fracture resistance of the outer enamel with aging [23,24], the degradation continues to within the region of decussation. Collectively, these results imply that while the largest degree of degradation with age occurs to the outer enamel, it extends over an appreciable depth that has not yet been defined. Future studies should explore the mechanisms responsible for the degradation in fracture resistance, as well as the progression of this degradation from the occlusal surface with chronological aging.

The reduction in fracture toughness of enamel with aging can influence the mechanics of crack growth within and about the surface of teeth [42]. These changes can be interpreted in terms of the degree of anisotropy exhibited by the fracture resistance of the two age groups. For example, the anisotropy in initiation toughness (ratio of $\mathrm{K}_{\mathrm{o}}$ for the longitudinal and transverse direction) increased from approximately 1.3 to 2.7 over the age span from the young to the old groups (approx. 40 yrs). In regards to the apparent fracture toughness, the degree of anisotropy in $\mathrm{K}_{\mathrm{c}}$ increased with aging as well from approximately 1.6 to 4.7 . Moreover, comparing the measures of $\mathrm{K}_{\mathrm{c}}$ for the two groups, the old enamel underwent approximately $30 \%$ and $70 \%$ reduction in the longitudinal and transverse directions, respectively. The increase in anisotropy signifies that the enamel is less resistant to transverse growth of surface cracks with aging. Furthermore, more extensive cracking is needed to dissipate an equivalent degree of fracture energy in the old enamel. This finding provides some explanation of why the teeth in seniors more frequently exhibit surface cracks and appear more susceptible to cracking than in young patients. It also identifies that the unique age-related degradation of the longitudinal and 
transverse directions serves to deflect the penetration of surface cracks from extension towards the tooth pulp.

The importance of the proteins to the fracture resistance of human enamel was recently investigated [32]. Extraction of the proteins resulted in approximately $40 \%$ reduction in the fracture toughness for both the longitudinal and transverse directions of crack growth. The proteins were found critical to the development of nanoscopic bridging ligaments, as well as those mechanisms operating at the meso-scale including crack deflection, branching and mineralized crack bridges. Considering the longitudinal direction of crack growth, there is no significant difference between the fracture toughness $\left(K_{c}\right)$ obtained for old enamel $(1.38 \pm 0.35$ $\left.\mathrm{MPa} \cdot \mathrm{m}^{0.5}\right)$ and that reported for enamel after removal of proteins $\left(\mathrm{K}_{\mathrm{c}}=1.24 \pm 0.25 \mathrm{MPa} \cdot \mathrm{m}^{0.5}\right)$. However, for the transverse direction of crack growth the $\mathrm{K}_{\mathrm{c}}$ of old enamel is approximately $60 \%$ lower than that reported for the deproteinized tissue [32]. Apparently there are more factors contributing to the degradation in crack growth resistance of enamel with aging than simply the loss of proteins.

There is an increase in the mineral density of enamel with aging [26,43], and a corresponding decrease in the volume of protein matrix. This reduction can occur from the consumption of substances that reduce the oral cavity $\mathrm{pH}$ [17] or as the result of restorative or cosmetic dental procedures such as teeth whitening [e.g. 44-46]. There are several other factors that can contribute to the reduction in fracture resistance of enamel with aging as well. At the crystal level there are two possible factors to consider. Due to the prolonged exposure to fluoride in the oral environment, there is a gradual replacement of the carbonated apatite crystallites of enamel over time with fluoro-apatite [47]. The presence of carbonates and fluoride ions causes structural disorders in the apatite crystals, followed by a loss in crystallinity [48]. Furthermore, 
the crystallites within enamel undergo an expansion with aging [49]. A recent study by Ghadimi et al. [50] reported that the indentation fracture resistance of enamel is inversely proportional to the size of the mineral crystals. Hence the increase in the crystallite dimensions and "densification" could contribute to the reduction of the inherent fracture toughness with age. Nevertheless, this interpretation neglects the potential diminished role of proteins in the fracture process with increasing age, which was identified to be an important factor on the age-related response.

Based on results of this initial study, the age-related degradation in fracture resistance of enamel does not appear to be as prominent as that in bone (e.g. [9]). Nevertheless, there are quite a few factors to consider in comparing aging of bone and enamel. For both tissues, donor age is just a quantitative manner to represent the groups of tissue and the time over which it may undergo structural changes. In the case of tooth tissues, third molars generally erupt by age 18 , so the donor ages are quite a bit greater than the true physical age of the enamel. Furthermore, contrary to what promotes the age-related changes in fracture behavior of bone, enamel is acellular and the aging process is not necessarily related to biological signals. While aging of bone does involve changes to the organic content that are critical to bone toughness [55, 56], it is not clear that the organic content in enamel undergoes changes, or that it is sufficient in content for changes to be a major contribution to fracture resistance. It is also worthwhile to reiterate that the oral cavity is chemically more diverse than that of the environment of bone. The variations in this environment between donors is an added complexity to the apparent aging process. Future work concerning the oral factors contributing to the apparent aging degradation of enamel is warranted. 
The results of this investigation make a fundamental contribution towards understanding fractures in human enamel and the impact of biological aging. However, there are some recognized limitations. One limitation is the source of the enamel samples that were evaluated. All of the experiments were performed on the cuspal enamel of third molars. It is not known whether the teeth were fully erupted, or if they were actively involved in occlusion. Moreover, no attention was placed on whether the tissue was obtained from the buccal or lingual cusps of the donor teeth. According to the literature, there are differences in the chemical composition and crystallite orientations amongst different teeth and their cusps, which is an important contributor to the mechanical properties of enamel [51-53]. Yet, a detailed analysis of the chemical composition of the young and old teeth was not performed. Previous studies have shown that there are spatial variations in the structure and composition of enamel $[51,57,58]$ and that they are important to the Young's modulus and hardness [51, 58]. In light of those findings, it would be more desirable to obtain a spatially resolved description of the structure and chemical composition of the enamel with respect to age, and couple that work with an equivalent evaluation of the distribution in fracture toughness. There have been attempts to characterize the spatial variations in fracture resistance of enamel with respect to age [23, 24], but these did not connect the findings with knowledge of structure and composition. Biswas et al [59] recently analyzed spatial variations in fracture behavior of enamel and degree of "biomineralization", but did not consider age. As previously described, an obstacle to performing spatially resolved evaluations of the fracture toughness in enamel is the concern with the indentation approach $[37,38]$. Clearly there is need for more work in this area.

The tooth enamel from each donor is exposed to a different oral environment and could contribute to the nature of changes that take place over time. Although it was shown that there a 
reduction in fracture resistance with aging, there are potentially other factors related to diet, health status and oral hygiene of the donors that could contribute to the responses obtained. As previously described, there are several processes that may affect the mineral and protein content of the enamel over one's lifetime. A recent study has shown that long-term radiotherapy treatment can cause denaturation of the enamel proteins, which deteriorates its mechanical properties and raises the susceptibility to dental caries [54]. These discoveries bring new challenges to the field of dentistry and expand the list of concerns regarding the contributions to changes in fracture resistance with aging.

This investigation explored the effects of aging on the fracture resistance of human enamel, and revealed that enamel becomes less resistant to crack growth with increasing patient age. However, it is not clear when the aging process reaches maturation or the relative importance of the participating factors on the rate of degradation. Further studies in this area are necessary for a better understanding of the chemical changes in old enamel and their impact on the mechanical behavior. Nevertheless, the results have potentially identified the need for developing alternative treatments for seniors, which accommodate for the lower resistance to fracture of the enamel.

\section{CONCLUSIONS}

Based on experimental results and a complementary finite element analysis of fracture in human enamel, there is a reduction in the crack growth resistance of this tissue with aging. For cracks extending along the axis of the rods, the fracture toughness of old enamel was $1.38 \pm 0.35$ $\mathrm{MPa} \cdot \mathrm{m}^{0.5}$, which was more than a $30 \%$ reduction from that of enamel from young adult teeth. For cracks extending transverse to the rods, the average apparent fracture toughness was $0.37 \pm$ 
$0.15 \mathrm{MPa} \bullet \mathrm{m}^{0.5}$, which was $70 \%$ lower than that of the young enamel. According to the cohesive zone analysis, the toughening achieved by crack growth bridging is severely degraded in the old enamel, as evidenced by a reduction in the crack closure stresses and the strain energy attributed to extrinsic toughening mechanisms. Furthermore, there was an increase in the degree of anisotropy of the fracture resistance with aging, which promotes an increase in cracking about the tooth's periphery. Overall, the degradation in resistance to fracture with aging increases the potential for fracture of natural tooth structure, especially in patients that develop large forces of mastication.

\section{ACKNOWLEDGEMENTS}

The authors acknowledge that this study was supported in part by the National Institutes of Dental and Craniofacial Research through grant (R01 DE016904) and the National Science Foundation (NSF DMR 1337727). The authors would also like to thank Ultradent Products Inc for supplying the Vit-l-escence resin composite.

\section{REFERENCES}

1. Eklund SA, Pittman JL, Smith RC. Trends in dental care among insured Americans: 1980 to 1995. J Am Dent Assoc. 1997; 128(2):171-8.

2. Murray PE, Stanley HR, Matthews JB, Sloan AJ, Smith AJ. Age related odontometric changes of human teeth. Oral Surg Oral Med Oral Pathol Oral Radiol Endod 2002; 93(4):474-82.

3. Lubisich EB, Hilton TJ, Ferracane J. Cracked Teeth: A review of the literature. Journal of Esthetic and Restorative Dentistry 2010; 22(3):158-67

4. Clark DJ, Sheets CG, Paquette JM. Definitive diagnosis of early enamel and dentinal cracks based on microscopic evaluation. J Esthet Rest Dent. 2003; 15(7):SI7-17.

5. Arola D. Fracture and Aging in Dentin. in Dental Biomaterials: Imaging, Testing and Modeling, R. Curtis and T. Watson ed., Woodhead Publishing, Cambridge, UK, 2007.

6. Zioupos P, Currey JD. Changes in the stiffness, strength, and toughness of human cortical bone with age. Bone 1998; 22(1):57-66. 
7. Yeni YN, Norman TL. Fracture toughness of human femoral neck: Effect of microstructure, composition, and age. Bone 2000; 26(5):499-504.

8. Nalla RK, Kruzic JJ, Kinney JH, Ritchie RO. Effect of aging on the toughness of human cortical bone: Evaluation by R-curves. Bone 2004; 35(6):1240-46.

9. Ager JW, Balooch G, Ritchie RO. Fracture, aging, and disease in bone. J Mater Res. 2006; 21(8):1878-92.

10. Kinney JH, Nalla RK, Pople JA, Breunig TM, Ritchie RO. Age-related transparent root dentin: mineral concentration, crystallite size, and mechanical properties. Biomaterials 2005; 26(16):3363-76.

11. Arola D, Reprogel R. Effects of aging on the mechanical behavior of human dentin. Biomaterials 2005; 26(18):4051-61.

12. Bajaj D, Sundaram N, Nazari A, Arola D. Age, dehydration and fatigue crack growth in dentin. Biomaterials. 2006;27(11):2507-17.

13. Nazari A, Bajaj D, Zhang D, Romberg E, Arola D. Aging and the reduction in fracture toughness of human dentin. J Mech Behav Biomed Mater 2009; 2(5):550-9.

14. Ivancik J, Majd H, Bajaj D, Romberg E, Arola D. Contribution of aging to the fatigue crack growth resistance of human dentin. Acta Biomater. 2012; 8(7):2737-46.

15. Robinson C, Kirkham J, Shore R. Dental Enamel Formation to Destruction. CRC Press; 1995.

16. White SN, Luo W, Paine ML, Fong H, Sarikaya M, Snead ML. Biological organization of hydroxyapatite crystallites into a fibrous continuum toughens and controls anisotropy in human enamel. J Dent Res 2001; 80(1):321-7.

17. Nanci A. Ten Cate's Oral Histology: Development, Structure, and Function. $7^{\text {th }}$ Edn. MosbyYear Book Inc; 2008.

18. Homma K. Historical studies on the Striae of Hunter-Schreger. Dent Jpn 1990; 27(1):141145.

19. Bajaj D, Arola D. On the R-curve behavior of human tooth enamel. Biomaterials 2009; 30(23-24):4037-46.

20. Chai H, Lee JJ, Lawn BR. On the chipping and splitting of teeth. J Mech Behav Biomed Mater. 2011; 4(3):315-21.

21. Yahyazadehfar M, Bajaj D, Arola D. Hidden contribution of the enamel rods on the fracture resistance of human teeth. Acta Biomater 2013; 9(1):4806-14.

22. Park, S, Wang DH, Dongsheng Z, Romberg E, Arola D. Mechanical properties of human enamel as a function of age and location in the tooth. J Mat Sci: Mat Med 2008a; 19(6):231724.

23. Zheng Q, Xu H, Song F, Zhang L, Zhou X, Shao Y, Huang D. Spatial distribution of the human enamel fracture toughness with aging. J Mech Behav Biomed Mater 2013; 26:148-54.

24. Park S, Quinn JB, Romberg E, Arola D. On the brittleness of enamel and selected dental materials. Dent Mater. 2008b;24(11):1477-85. 
25. Bajaj D, Nazari A, Eidelman N, Arola D. A comparison of fatigue crack growth in human enamel and hydroxyapatite. Biomaterials 2008; 29(36):4847-4854.

26. He B, Huang S, Zhang C, Jing J, Hao Y, Xiao L, Zhou X. Mineral densities and elemental content in different layers of healthy human enamel with varying teeth age. Arch Oral Biol. 2011; 56(10):997-1004.

27. Zhang D, Nazari A, Soappman M, Bajaj D and Arola D. Methods for examining the fatigue and fracture behavior of hard tissues. Exp Mech 2007; 47(3):325-36.

28. Yahyazadehfar M, Nazari A, Kruzik JJ, Quinn GD, Arola D. An Inset CT specimen for evaluating fracture in small samples of material. J Mech Behav Biomed Mater 2014a; 30: 358-68.

29. Ang SF, Bortel EL, Swain MV, Klocke A, Schnieder GA. Size-dependent elastic/inelastic behavior of enamel over millimeter and nanometer length scales. Biomaterials 2010; 31(7): 1955-63.

30. Bajaj D. Crack Growth Resistance of human Tooth Enamel: Mechanism of Toughening and Energy Dissipation. Ph.D. Dissertation, University of Maryland, Baltimore County, Ann Arbor: ProQuest/UMI; 2010.

31. Bechtle S, Habelitz S, Klocke A, Fett T, Schneider GA. The fracture behavior of dental enamel. Biomaterials 2010; 31(2):375-84.

32. Yahyazadehfar M, Arola D. The role of organic proteins on the crack growth resistance of human enamel. Acta Biomaterialia 2015;19:33-45.

33. Ramberg W, Osgood WR. Description of stress-strain curves by three parameters. NACA (technical note) 1943; 902: (19930081614)1-28.

34. Lawn BR, Lee JJW. Analysis of fracture and deformation modes in teeth subjected to occlusal loading. Acta Biomaterialia 2009a; 5(6):2213-21.

35. Anderson TL. Fracture mechanics fundamentals and applications. $3^{\text {rd }}$ Ed., Boca Raton, FL: CRC Press; 2005.

36. Hassan R, Caputo AA, Bunshah RF. Fracture toughness of human enamel. J Dent Res. 1981; 60(4):820-7.

37. Quinn GD, Bradt RC. On the Vickers indentation fracture toughness test. J Am Cer Soc. 2007; 90(3):673-80.

38. Kruzic JJ, Kim DK, Koester KJ, Ritchie RO. Indentation techniques for evaluating the fracture toughness of biomaterials and hard tissues. Journal of Mechanical Behavior of Biomedical Materials 2009; 2(4):384-95.

39. Munz D. What can we learn from R-curve measurement? J Am Cer Soc 2007; 90(1):1-15.

40. Barani A, Chai H, Lawn BR, Bush MB. Mechanics analysis of molar tooth splitting. Acta Biomater. 2015;15:237-43.

41. Chai H. On crack growth in molar teeth from contact on the inclined occlusal surface. J Mech Behav Biomed Mater. 2015;44:76-84. 
42. Yahyazadehfar M, Ivancik J, Majd H, An B, Zhang D and Arola D. On the mechanics of fatigue and fracture in teeth. Appl Mech Rev 2014b; 66(3): 030803.

43. Bertacci A, Chersoni S, Davidson CL, Prati C. In vivo enamel fluid movement. Eur J Oral Sci 2007; 115(3):169-73.

44. Efeoglu N, Wood D, Efeoglu C. Microcomputerised tomography evaluation of $10 \%$ carbamide peroxide applied to enamel. J Dent. 2005; 33(7):561-7.

45. Jiang T, Ma X, Wang Y, Tong H, Shen X, Hu Y, Hu J. Investigation of the effects of 30\% hydrogen peroxide on human tooth enamel by Raman scattering and laser-induced fluorescence. J Biomed Opt 2008; 13(014019):1-9.

46. Wang X, Mihailova B, Klocke A, Fittschen UE, Heidrich S, Hill M, Stosch R, Güttler B, Broekaert JA, Bismayer U. Side effects of a non-peroxide-based home bleaching agent on dental enamel. J Biomed Mater Res A. 2009;88(1):195-204.

47. Brudevold F, Aasenden R, Bakhos Y. A preliminary study of posteruptive maturation of teeth in situ. Caries Res. 1982; 16(3):243-48.

48. Leventouri Th, Antonakos A, Kyriacou A, Venturelli R, Liarokapis E, Perdikatsis V. Crystal structure studies of human dental apatite as a function of age. International Journal of Biomaterials 2009; 2009:698547.

49. Legeros RZ. Apatite in biological systems. Prog Crystal Growth Char 1981; 4(s1-2):1-45.

50. Ghadimi E, Eimar H, Song J, Marelli B, Ciobanu O, Abdallah MN, et al. Regulated fracture in tooth enamel: a nanotechnological strategy from nature. J Biomech. 2014; 47(10):2444-51.

51. Cuy JL, Man AB, Livi KJ, Teaford MF, Weihs TP. Nanoindentation mapping of the mechanical properties of human molar tooth enamel. Arch Oral Biol. 2002; 47(4):281-291.

52. Braly A, Darnell LA, Mann AB, Teaford MF, Weihs TP. The effect of prism orientation on the indentation testing of human molar enamel. Arch Oral Biol. 2007; 52(9):856-60.

53. He LH, Swain MV. Understanding the mechanical behavior of human enamel from its structure and composition characteristics. J Mech Behav Biomed Mater. 2008; 1(1):18-29

54. Reed R, Xu C, Liu Y, Gorski JP, Wang Y, Walker MP. Radiotherapy effect on nanomechanical properties and chemical composition of enamel and dentin. Arch Oral Biol 2015;60(5):690-7.

55. Wang X, Shen X, Li X, Agrawal CM. Age-related changes in the collagen network and toughness of bone. Bone 2002;31(1):1-7.

56. Zioupos P, Currey JD, Hamer AJ. The role of collagen in the declining mechanical properties of aging human cortical bone. J Biomed Mater Res. 1999;45(2):108-16.

57. McGuire JD, Walker MP, Mousa A, Wang Y, Gorski JP. Type VII collagen is enriched in the enamel organic matrix associated with the dentin-enamel junction of mature human teeth. Bone. 2014;63:29-35.

58. Xu C, Reed R, Gorski JP, Wang Y, Walker MP. The Distribution of carbonate in enamel and its correlation with structure and mechanical properties. J Mater Sci. 2012;47(23):8035-8043. 
59. Biswas N, Dey A, Kundu S, Chakraborty H, and Mukhopadhyay AK. Mechanical properties of enamel nanocomposite. 2013, Article ID 253761, 15 pages. 


\section{Tables}

Table 1. Comparison of the fracture behavior of young and old enamel in the two directions of crack growth.

Table 2. Finite element results for the components of fracture energy and toughness for the old enamel. 
Table 1.

\begin{tabular}{c|l|cc}
\hline \multirow{2}{*}{ Direction } & \multicolumn{1}{|c|}{ Parameters } & \multicolumn{2}{|c}{ Age Group } \\
& & Young & Old \\
\hline \hline \multirow{3}{*}{ Longitudinal } & $\mathbf{K}_{\mathbf{o}}\left(\mathrm{MPa} \bullet \mathrm{m}^{0.5}\right)$ & $0.73 \pm 0.14$ & $0.78 \pm 0.05$ \\
& $\mathbf{K}_{\mathbf{q}}\left(\mathrm{MPa} \bullet \mathrm{m}^{0.5} / \mathrm{mm}\right)$ & $2.66 \pm 0.42$ & $0.64 \pm 0.44$ \\
& $\mathbf{K}_{\mathbf{c}}\left(\mathrm{MPa} \bullet \mathrm{m}^{0.5}\right)$ & $2.05 \pm 0.19$ & $1.38 \pm 0.35$ \\
\hline \multirow{3}{*}{ Transverse } & $\mathbf{K}_{\mathbf{o}}\left(\mathrm{MPa} \bullet \mathrm{m}^{0.5}\right)$ & $0.54 \pm 0.11$ & $0.37 \pm 0.15$ \\
& $\mathbf{K}_{\mathbf{g}}\left(\mathrm{MPa} \bullet \mathrm{m}^{0.5} / \mathrm{mm}\right)$ & $1.05 \pm 0.26$ & - \\
& $\mathbf{K}_{\mathbf{c}}\left(\mathrm{MPa} \bullet \mathrm{m}^{0.5}\right)$ & $1.23 \pm 0.20$ & $0.37 \pm 0.15$
\end{tabular}


Table 2.

\begin{tabular}{|c|c|c|}
\hline Parameters & Young enamel & Old enamel \\
\hline $\mathbf{J}_{\text {tip }}$ & 85.8 & 53.7 \\
\hline $\mathbf{J}_{\mathbf{P I}}$ & 7.8 & 4.6 \\
\hline $\mathbf{J}_{\mathrm{br}}$ & 37.2 & 27.3 \\
\hline$J_{\text {total }}$ & 130.8 & 85.6 \\
\hline $\mathbf{K}_{\text {LEFM }}$ & 1.68 & 1.26 \\
\hline$K_{\text {eff }}$ & 2.08 & 1.68 \\
\hline
\end{tabular}

Units for $\mathrm{J}$ and $\mathrm{K}$ are $\mathrm{Pa} \bullet \mathrm{m}$ and $\mathrm{MPa} \bullet \mathrm{m}^{1 / 2}$, respectively.

I. $\mathrm{J}_{\text {tip }}$ is the fracture energy estimated for linear elastic behavior. It is used to calculate $\mathrm{K}_{\mathrm{c}}$

II. $J_{\mathrm{pl}}$ accounts for the energy spent in plastic deformation

III. $J_{b r}$ is the energy stored in the spring elements

IV. $J_{\text {total }}$ is the total fracture energy and it is used to calculate $K_{\text {eff }}$ 


\section{Figures}

Figure 1. Specimen preparation, geometry and testing orientations. a) Bucal-lingual section of molar with potential inset of occlusal enamel highlighted. Note the Longitudinal (L) and Transverse (T) directions of crack growth. The letters "o" and "i" refer to the outer and inner enamel, respectively. b) Geometry of inset CT specimen. The molded enamel inset is approximately $2 \times 2 \times 2 \mathrm{~mm}^{3}$ and embedded within a dental resin composite. All dimensions are in millimeters. c) Relative placement of the back channel in enamel inset for the longitudinal and transverse crack growth directions. The arrows indicate the direction of crack growth. For the transverse direction, samples are shown for crack growth within outer enamel.

Figure 2. Details of the finite element model. a) Geometry of the inset CT specimen b) Crack tip mesh (element type CPE8R) c) Expected stress-strain curve for enamel and Ramberg-Osgood curve fitting d) Constitutive behavior of springs used to model extrinsic toughening.

Figure 3. Load versus load-line displacement distributions for crack extension in the longitudinal direction within enamel inset CT specimens. Examples are show for representative young and old specimens.

Figure 4. Crack growth resistance of the enamel. a) Representative crack growth resistance curve (R-curve) for the longitudinal direction in an old specimen. The quantities $\mathrm{K}_{\mathrm{o}}, \mathrm{K}_{\mathrm{g}}, \mathrm{K}_{\mathrm{c}}$ represent the initiation, growth and fracture toughness, respectively. b) A comparison of the crack growth resistance in the longitudinal direction for young and old specimens. c) A comparison of the crack growth resistance in the transverse direction for young and old specimens. The dashed line demarcates the mean fracture toughness of the old specimens.

Figure 5. A comparison of the fracture behavior for the young and old specimens in the two directions of crack growth. a) The initiation toughness $\left(\mathrm{K}_{\mathrm{o}}\right)$, b) growth toughness $\left(\mathrm{K}_{\mathrm{g}}\right)$, and c) fracture toughness $\left(\mathrm{K}_{\mathrm{c}}\right)$.

Figure 6. Hybrid method and cohesive zone analysis. a) A comparison of the crack opening displacement profiles from the experiments and finite element models for a young specimen. b) A comparison of the crack opening displacement profiles from the experiments and finite element models for an old specimen. The crack profile is shown from the symmetry plane (i.e. $\mathrm{COD} / 2$ ) for longitudinal crack growth. Note that inelastic deformation occurring in front of the crack tip was defined for both traction-free and cohesive model simulations. c) A comparison of the Crack Closure Stress (CCS) profiles for young and old enamel as a function distance from crack tip.

Figure 7. Micrographs documenting crack growth in the longitudinal direction in old enamel. a) Representative path of crack growth in a specimen from a 59 year old donor. The arrow indicates the direction of crack growth. b) Magnified view of the toughening mechanisms in the longitudinal direction. 
Figure 8. Micrographs documenting crack growth in the transverse direction in old enamel a) a representative path of growth path in a specimen from a 64 year old donor. The arrow indicates the direction of crack growth. b) A magnified view of crack extension along the inter-rod region in the transverse direction. 


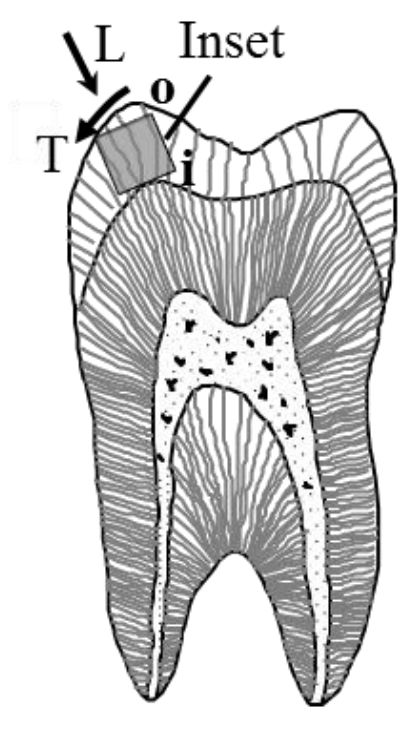

a)
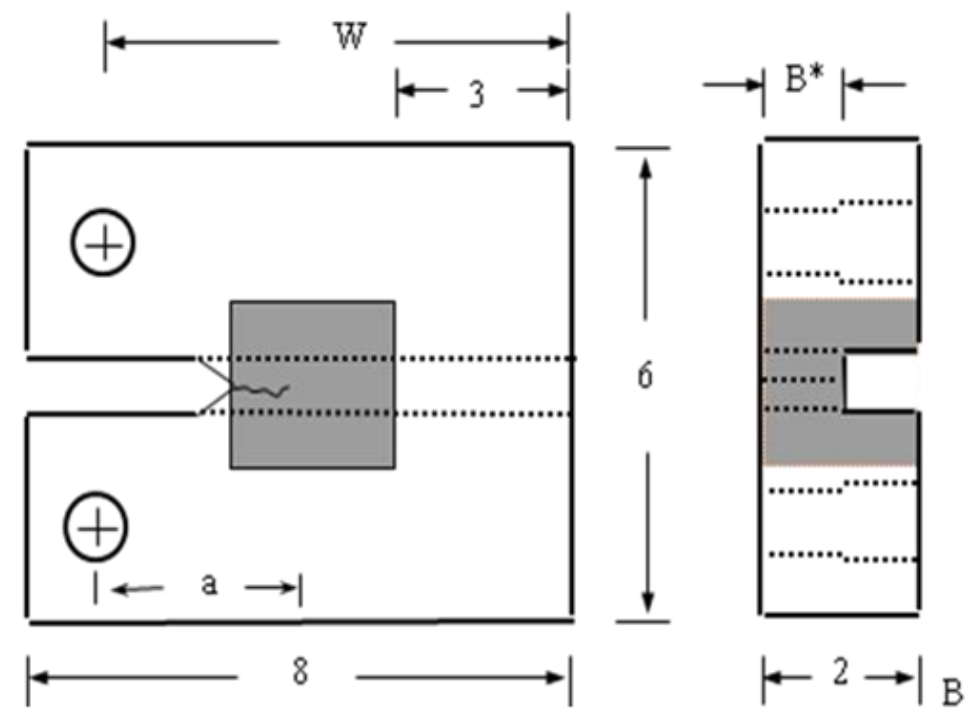

b)

\section{$\underline{\text { Longitudinal direction }}$}

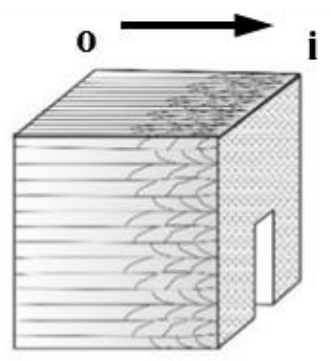

Crack growing from outer to inner enamel

\section{$\underline{\text { Transverse direction }}$}

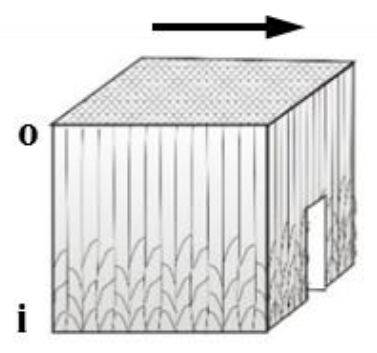

Crack growing in outer enamel

c)

Figure 1. 
a)

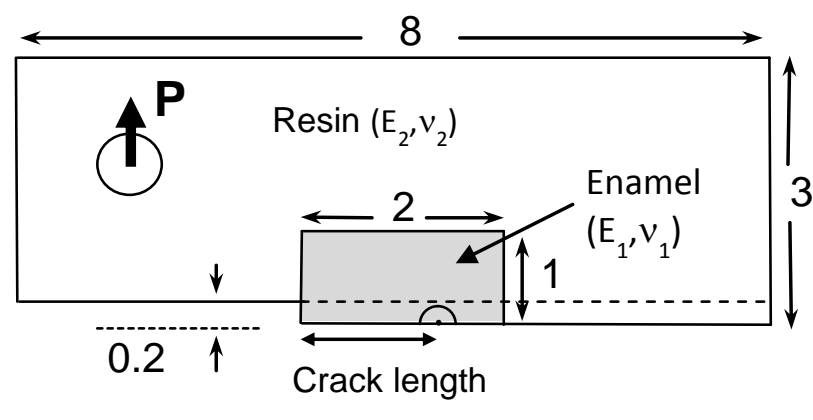

b)
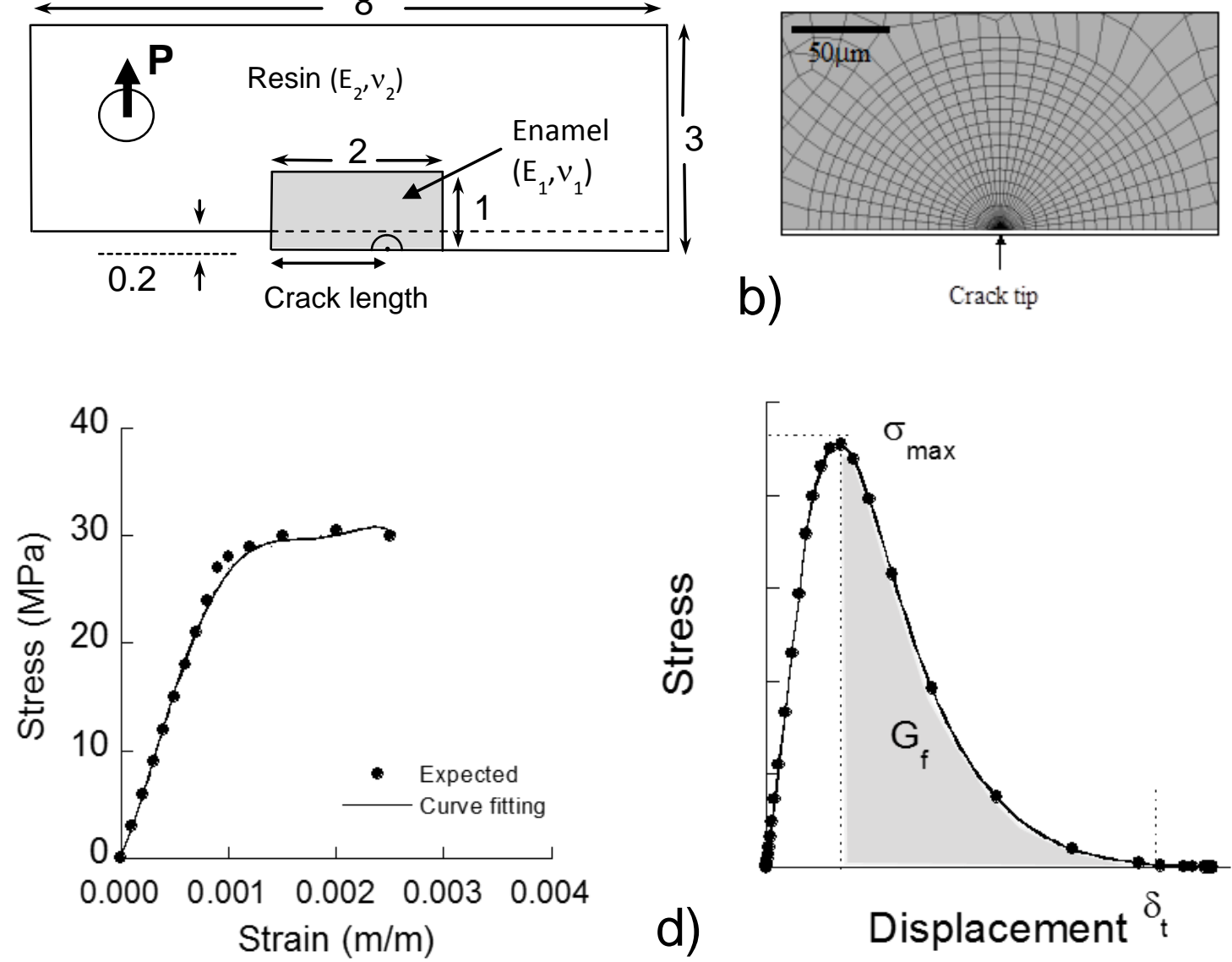

Figure 2. 


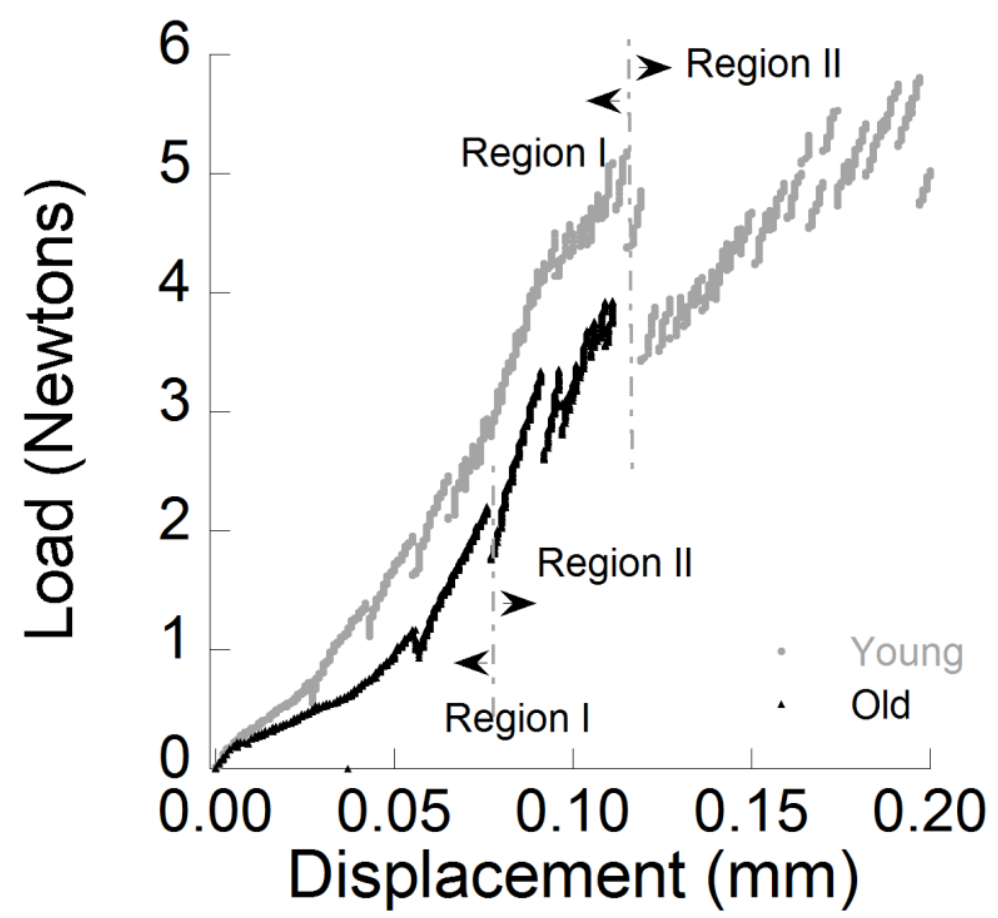

Figure 3. 

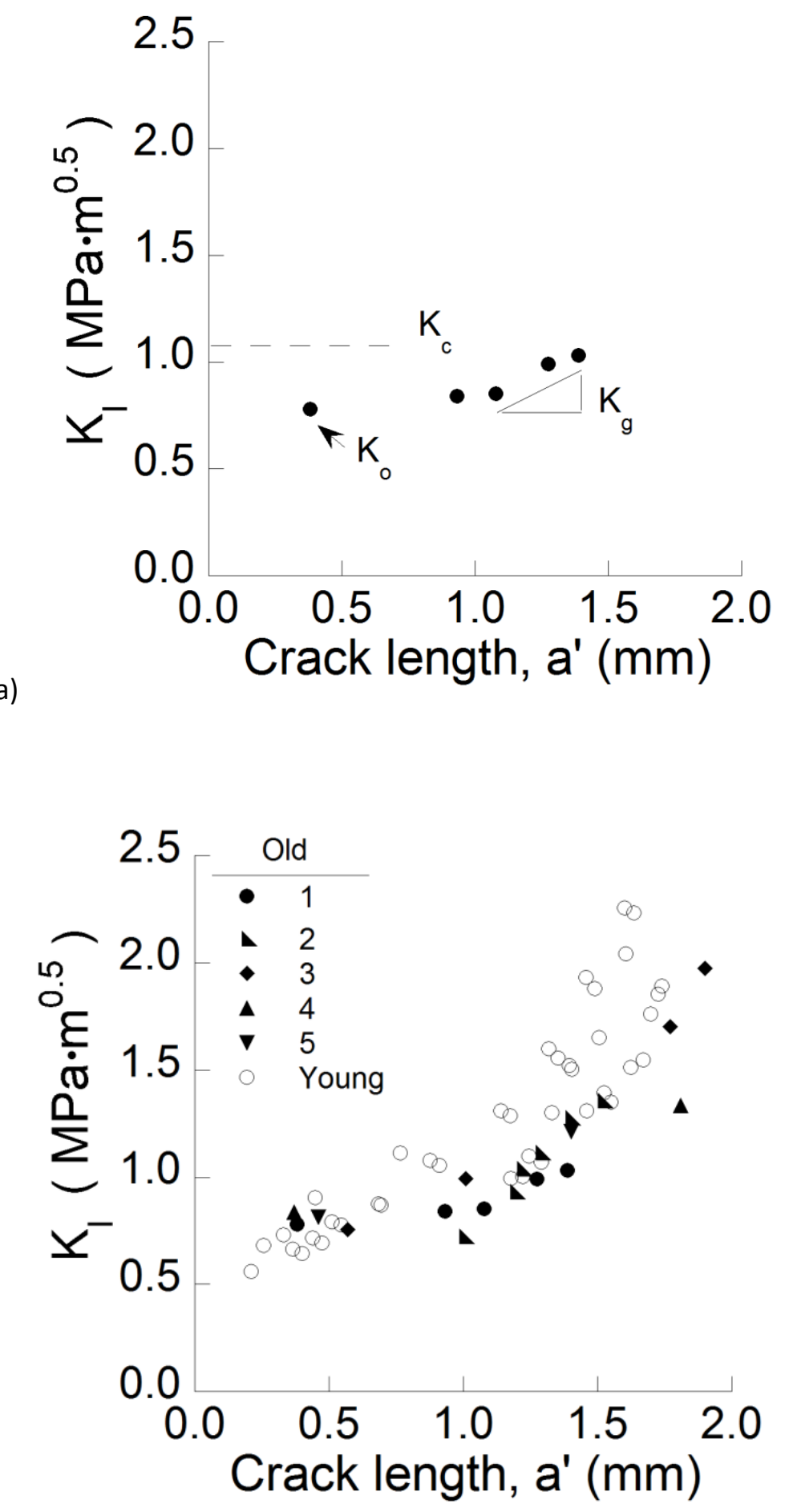

b)

Fig. $4-$ 


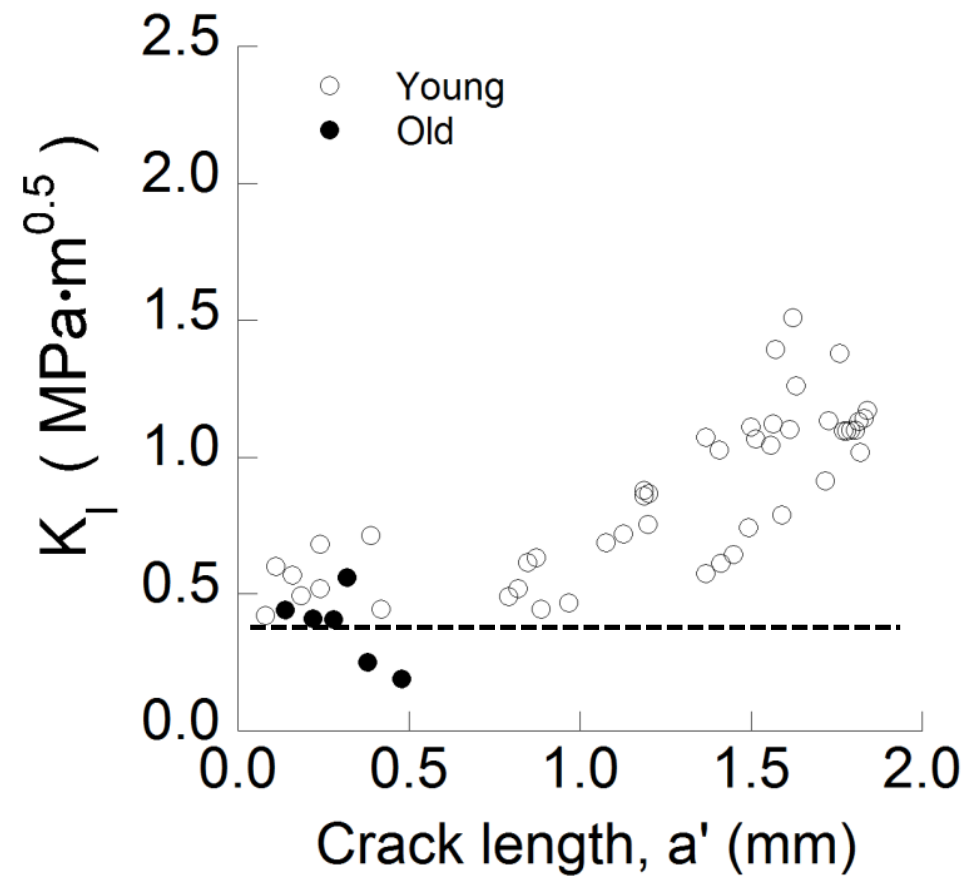

c)

Figure 4. 


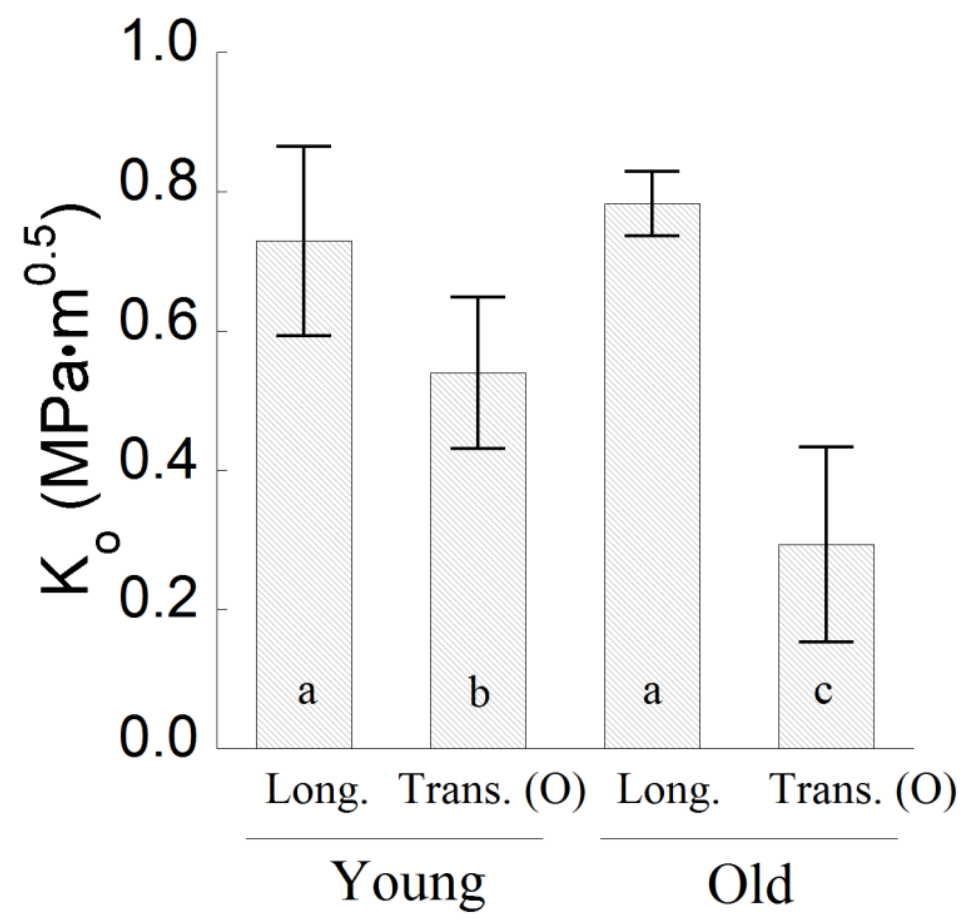

a)

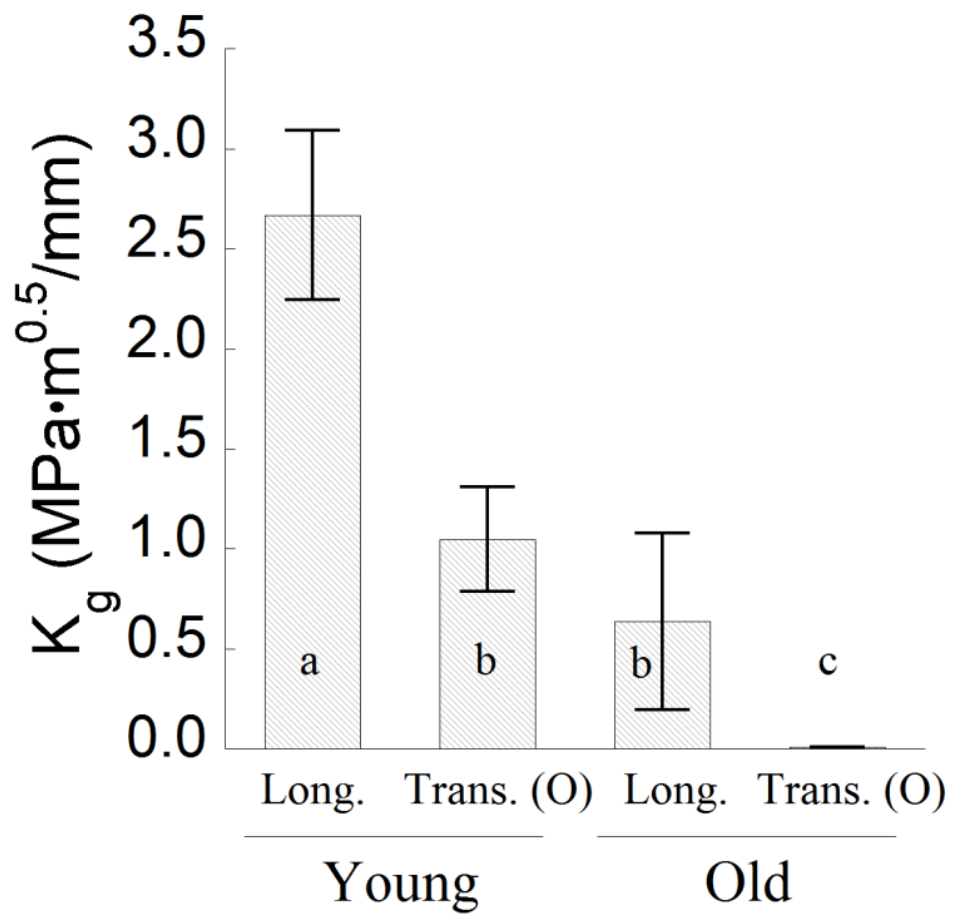

b)

Fig. 5 - 


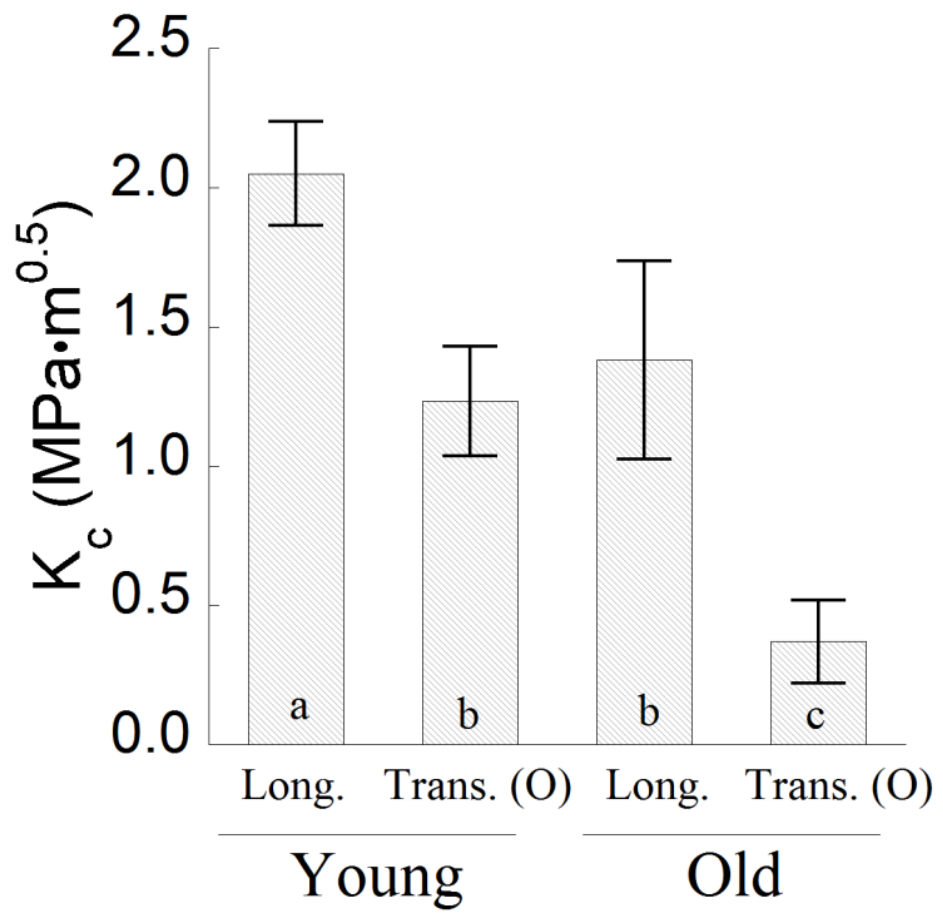

c)

Figure 5. 


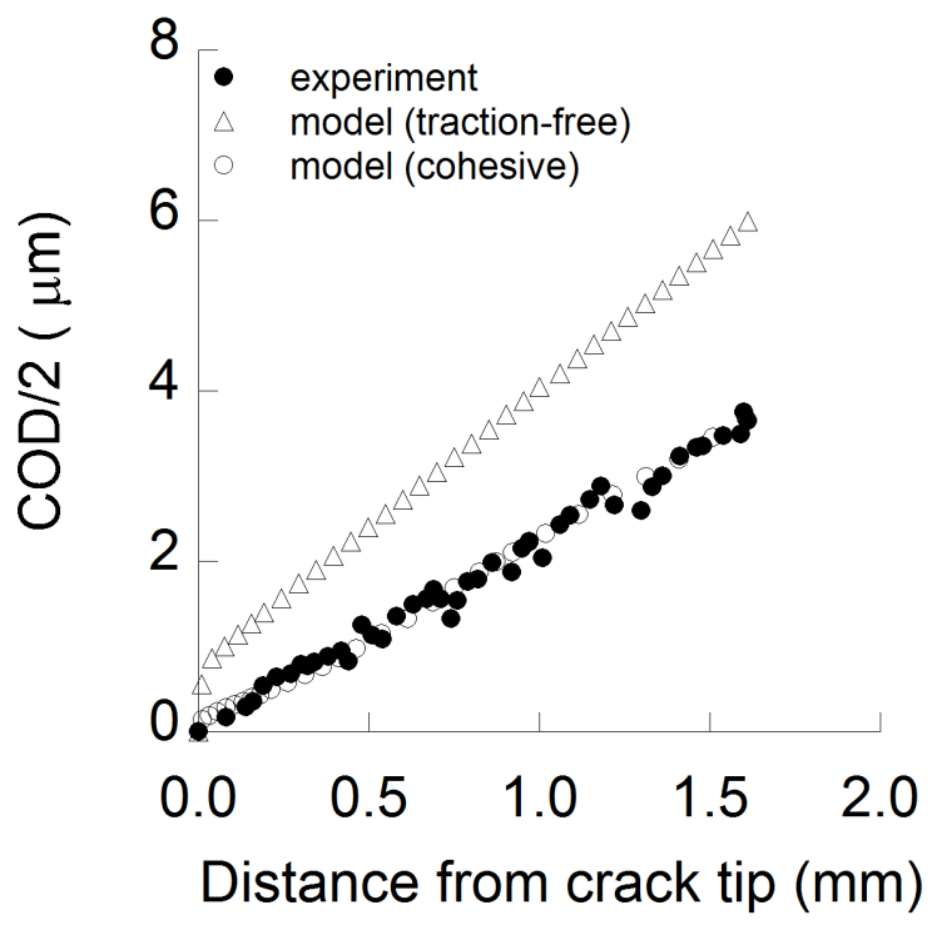

a)

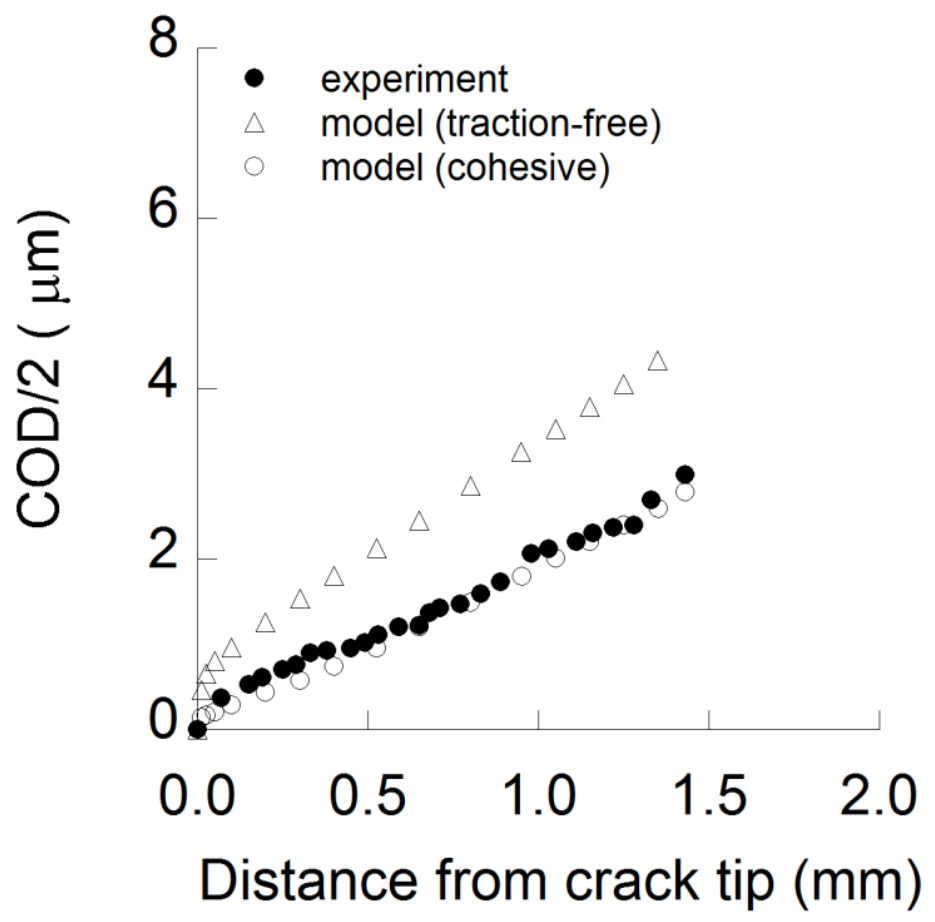

b) 


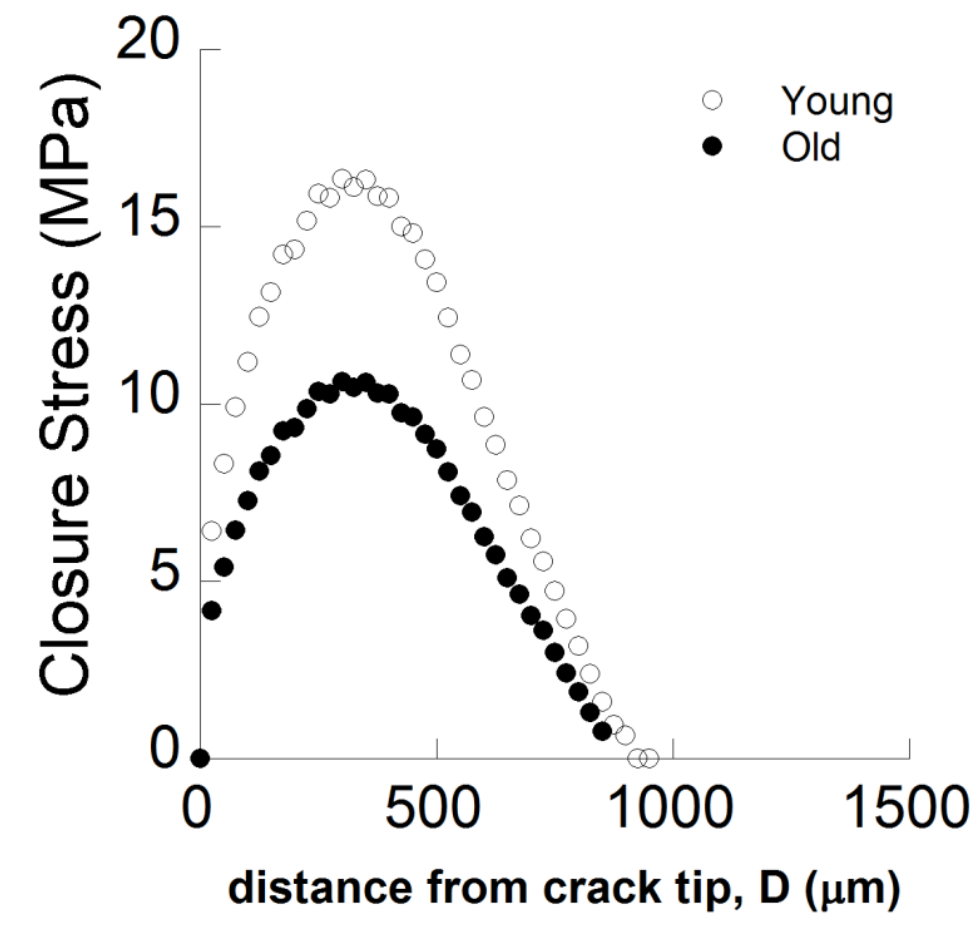

c)

Figure 6. 

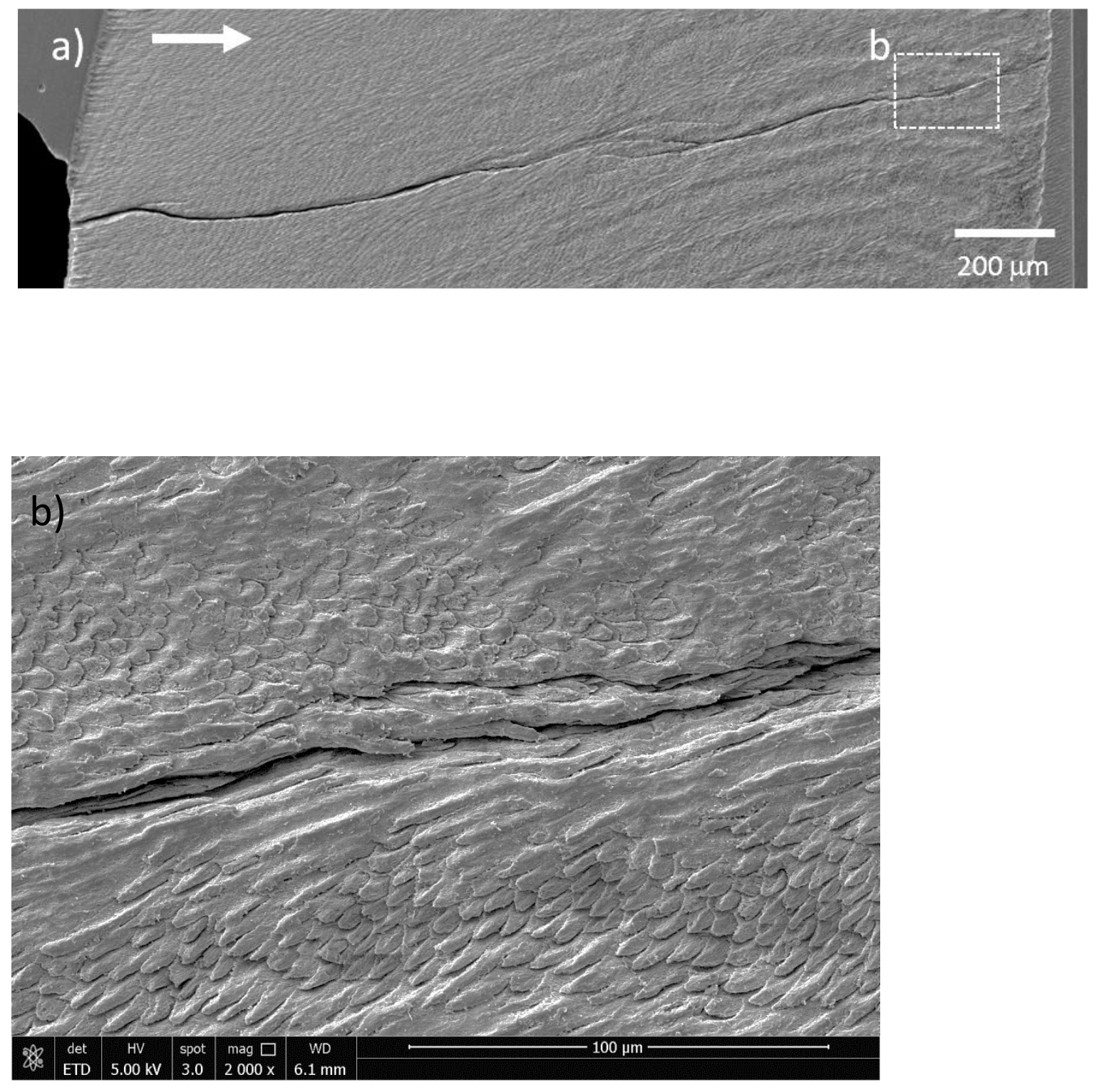

Figure 7. 

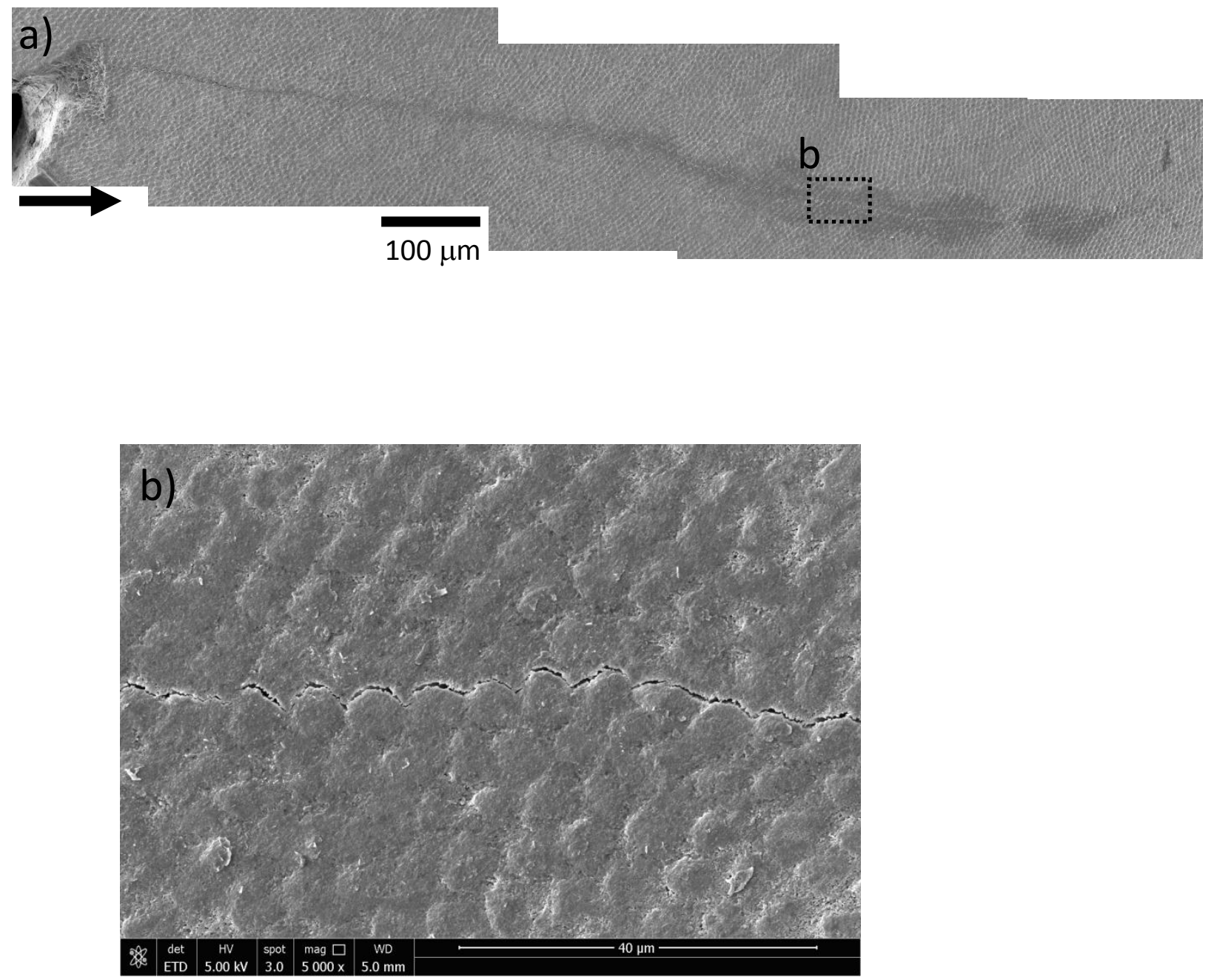

Figure 8. 

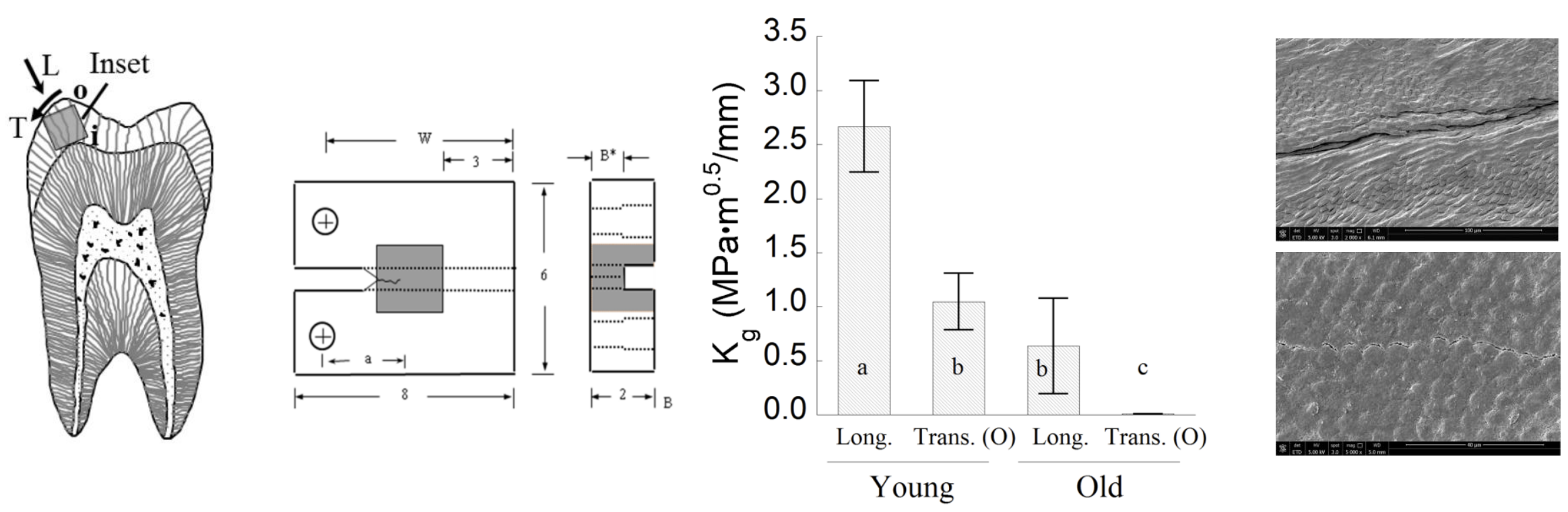